\title{
On the Relationship of Class Conversation and Pragmatic Ability in the Primary School
}

\author{
Zhen Zhou \\ Foreign Languages College, Nanchang Normal University, Nanchang, Jiangxi, 330032 \\ zoye100@sina.com
}

Keywords: Pragmatic ability; Class conversation; Pupil; Heuristic; Student-centered

\begin{abstract}
It is well-known that the English conversation is of great importance to promote students' English pragmatic ability. However, at present, there exist many problems impeding the carrying out of the effective class conversation and the development of students' pragmatic ability. This article firstly analyzes the current problems influencing the class conversation, then explores the class conversation in the background of new curriculum and attempts to find the right ways to carry out effective class conversation to promote students' pragmatic ability. The article finally puts forward two ways, that is, creating real or semi-real situations and posing heuristic questions to foster students' pragmatic ability. The article attempts to improve the current situations of ineffective class conversation and promote students' English pragmatic ability, and to improve the primary English teaching efficiency.
\end{abstract}

\section{Introduction}

Brazil educator Paul once remarked that if there is no conversation, there is no communication. And since there is no communication, there is no real education. In essence, teaching is a process of communication and is a conversational activity, which should be also a process where the teacher and students create together through conversation and communication. Any language knowledge skills, affect and values should be nurtured, produced and developed in some communicative situations. The new curriculum reform advocates that the English class should implement real conversation. Therefore the English teacher should care about every student's development, let students learn effectively in interaction and conversation, improve students' ability of listening and speaking, promote their conversational skill, and ultimately acquire and use the language fluently and skillfully, attaching much importance to the interaction and conversation between the teacher and students and among students.

\section{The Present Problem Affecting the Class Conversation}

As the curriculum reform deepens and widens, teachers spend a lot of time and energy researching and optimizing class conversation in the primary school. The class conversation has experienced quality changes, but there also exists some unsatisfactory class conversation, which greatly influences students' pragmatic ability development.

Class Conversation Pursuing Superficial Hilarity. Although the English class of "Only the teacher talks" has been completely denied, yet the teacher still controls the class questioning strongly. In order to activate the class atmosphere and stimulate students' learning initiatives, some teachers often rack their brains to design a lot of questions to ask students. In the English class, the teacher asks questions constantly, and students answer questions quickly. Sometimes, some teachers even do not take the quality of questions into consideration, and students are passive. In this case, it restricts students' pragmatic ability cultivation and development. If the teacher possesses the awareness of interactive communication, there will be no phenomenon of "whole-class questioning", and there will be no ineffective questioning to occupy the limited class teaching time and the efficiency of class conversation can be greatly improved. 
Class Conversation Neglecting Eliciting Teaching. The class questioning should be heuristic, which can arouse or promote students' active thinking. But in reality, many conversations are unilateral, and the class conversation goes only with the teacher's thought. Some teachers think that if there is questioning and answering, that is successful conversation. They design mostly closed questions, the answers can be found directly from the passage, and some questions are even simple "yes or no" questions. Many teachers pay too much attention to the language structure, but neglect the language function. So students can answer questions without thinking, and they are just repeating. In this way, the class conversation has no communicative meaning. The effective class should require the teacher's questions supply students with thinking space and let students fly their imagination and seek the creative answer rather than the standard answer.

Class Conversation Neglecting Teaching Production. The new curriculum reform calls for class production and objects to it that teachers take pre-designed answers or expected result as students' production, and that teachers purposely guide students to one standard answer. But the realistic teaching is really disappointing and worrying. The teaching practice tells us interaction is the biological condition to foster students' pragmatic ability. In the teaching, the teachers should be good at designing activities circling the text content, realize the interaction between the teacher and students, students and students, students and the text, carry out discussion, and improve students' comprehensive language using ability. The English teacher should give positive approval and encouragement to students' answers, and in this way, students' thinking flames can be ignited, and the interaction between the teacher and students can be more wonderful and students' language ability can develop well.

Ineffective Situation Creation and Ineffective Conversation. Firstly, false situation creation affects students' pragmatic ability. The process of language communication is a contextualized process. And context is what pragmatics is concerned about. To foster students' pragmatic ability, the most important thing is to create real or semi-real situation. The English curriculum also points out that teachers should let students experience and study language in the real context. If teachers create false situations, what students learn is useless in the real life. Secondly, in the English teaching, the teacher should create situation to let students understand the learned language knowledge better and acquire the learned knowledge. The index to measure the quality of teaching situation is that students' understanding of context's inner implication and its transmitted language information is consistent with the purpose the teacher creates the context. Although the ineffective situation and conversation can create hilarious atmosphere, yet it is actually ineffective. And students can not acquire the language successfully in such a situation.

\section{The Class Conversation in the Context of New Curriculum}

Class Conversation Advocating Equality between the Teacher and Students. In the context of new curriculum, the unilateral language communication mode of traditional "You say, I listen" is deserted and the equality of the teacher and students, and democratic class conversation are advocated. The class conversation is a process in which the teacher and students seek truth together and construct values. It is also a process in which for the two parties to open their heart and communicate mutually. In the class conversation, students are no passive receivers or listeners, and they are democratic, cooperative conversationers who are equal to teachers and respect teachers. On the influence of the conversational spirit, the teacher and students, students and students communicate as to the teaching content frankly, and they learn from each other.

Class Conversation Calling for Creative Spirit. The traditional English class mainly focuses on questions and students just try to find out the set answers. The new type English conversation takes "heuristic" as its soul, emphasizes activating students' awareness of "master of study", develops students' dominant role, guides students to question based on comprehension and seek similarities from differences and creates from inheriting. The design of questions should be open and exploring, encouraging students to explore independently. The new class conversation mode brings students 
broader thinking space and makes students "producer of knowledge" rather than only "container" of receiving knowledge.

Class Conversation Pursuing Multiple Cooperation and Interaction. The class conversation in the new curriculum is a process of active interaction between the teacher and students, students and students, and their development. The class conversation should not only stress cultivating students' independent and self-reliant ability, but also training students' cooperative and interactive ability. The class conversation must be based on multiple communication, eliciting mutual complementing between the teacher and students, and between students. The teacher and students should share their thought, experience, knowledge, concept, circling the common topic to enrich the teaching content, explore new discoveries, and rectify their respective cognitive misunderstanding, have new perspectives and gain new possibilities to seek the truth.

Class Conversation Based on Real Situation Being the Rich Earth to Foster Students' Pragmatic Ability. Situational conversation is the effective carrier of cultivating students' pragmatic ability. PEP textbook supplies a lot of topics close to students' learning and life, and establishes a good platform for the conversation between the teacher and students. In the class teaching, we should care more about creating daily life contexts, activating students' interest, leading-in the conversation topic, and integrate to English conversation teaching naturally. And the teacher should let students perceive learning content in the real language environment close to life, which is useful to improve students' comprehension and the ability to grasp conversation content. Through class conversation, we can train students' conversation skills and English pragmatic skills.

Class Conversation Based on Equal Communication Being the Condition to Improve Students' Pragmatic Ability. The class conversation model should be based on parallel communication and is bilateral mutual communication. This kind of communication, is a parallel, equal, democratic, real, and active communication. In the communication, the teacher and students are the center, communicating for the same purpose. Parallel communicative class conversation is helpful to stimulate students' inner motivation of learning a language, to activate students' communicative desire to active participation, strengthen students' oral English expression confidence, and let them be always in a state of actively accept new language information and ultimately realize communication of the class teaching. When the students' language input achieves a certain amount, it will have quality change, and students language output comes into being naturally and their language ability is developed.

Class Conversation Based on Cooperation and Interaction Being the Core of Fostering Students' Pragmatic Ability. The teacher carries out conversation in the interaction circling the text content, which can encourage students to have conversation in their self-regulated discussion, promote conversation and promote students' comprehension language using ability development. Much practice experience tells us a class with no production is an ineffective class. Only the class with production of knowledge, skill and affect is an effective class.

\section{Strategies to Optimize Class Conversation and Cultivate Students' Pragmatic Ability}

Changing Teaching Ideas and Improving Pragmatic Awareness. The ultimate goal of students to learn English is to form comprehensive using ability and master idiomatic English. But the traditional language learning neglects the English pragmatic ability cultivation, and the teachers often only stress the English grammar and vocabulary knowledge and acquiring of the skills of listening, speaking, reading and writing. They do not care about how learners use the knowledge and skills to do things in specific communicative environment. Practice proves that the acquisition of the pragmatic ability is much more important than the learning of pronunciation, grammar and vocabulary. Because, even if our English is grammatically right, and our pronunciation is accurate, yet we can not communicate with English native speakers effectively. And sometimes, our verbal behavior is thought to be rude and improper. 
As for the English teachers, they should transform their conception and improve their pragmatic awareness. Only their awareness is changed, can they strengthen their pragmatic theoretical study, put the theory into practice, examine the English teaching from the angle of pragmatic actively, correct the errors of the teaching content and teaching forms, and let students get in touch with original English. In the meantime, the teachers should guide students to build up pragmatic awareness and not to only memorize the knowledge mechanically. In the process of learning English knowledge, we should consider the used context more and imagine the context actively and try to apply what we have learned.

Teaching Pragmatic Knowledge to Consolidate Students' Language Basis. One important measure of improving students' pragmatic ability is to let students get in touch with the culture and communicative norms of the English countries. Language is the carrier of culture and culture has clear feature of nationality and uniqueness. Hence, different languages have big differences because of different cultural background, and there also exist huge difference in the language use. The language communication is also cultural clash and integration. In the level of pragmatics, cultural values and verbal behaviors affect each other. So the language teaching should be culture-oriented and help learners to know and tolerate the differences. In the daily class conversation, the teacher should try to activate the textbook content, make cultural comparison, and help students understand cultural similarities and differences. In the class conversation, the teacher can let students know the cultural differences through designing some special social cultural atmosphere, letting students do "role play". From the vivid experiencing, the teacher can add students' English learning interest, have an experiential knowledge of life style, norms and values of the western society, strengthen students' knowledge of English essence, and ultimately improve students' English pragmatic ability to use English more accurately, properly and well.

Real Situation Being the Rich Earth to Cultivate Students' Pragmatic Ability. Firstly, the context creation should achieve the teaching aims and bridge the language knowledge and practice. Hence, in our teaching, teachers should look into the textbook, grasp the language foci and choose suitable situation targetedly and realize that the creation of situations serves the students' language acquisition. Secondly, the creation of situations should be close to students' life. Creating situations must consider students' current level, fit their cognitive developing rules, cater for different levels of students and complete the meaning construct of language knowledge. The language drill of teaching situation not only contains the familiar or understandable content, but also challenging and interesting content, which can help to foster students' pragmatic ability. Moreover, creating situations must consider pupils' age. To pupils in lower grades, teachers can create fairy tale situation which is interesting and funny. As for pupils in higher grades, the teacher can create more difficult situations, such as, survey, speech, festival party to enthuse them to study English.

Heuristic Questioning Being the Key to Foster Students' Pragmatic Ability. Conversation is one of the main channels of education. And questioning is the key to make conversation effective. Questioning should take "elicit thinking" as its soul. As English teachers, they should be not only a knowledge transmitter, but also be raiser of effective questions. In class, the teachers not only stimulate students to think, but also should encourage students to put forward questions. The design of questions should abide by language acquisition rule, reflecting layers and difficulty. The value or level of a question lies in that eliciting can leave thinking space. The wider and freer the space the questions bring to the students, the richer the students' thinking fruit would be. In the class teaching, teachers should use the method of gradual deepening of difficulty to design questions, elicit and lead students timely, stimulate students' thinking and in this way, wonderful class conversation will emerge.

\section{Conclusions}

The class conversation is of great importance to limited English class. As for the English teachers, they should have the awareness of language pragmatics, and have solid pragmatic knowledge. They 
should carry out pragmatic awareness into every detailed specific class, try their best to create situations, design questions effectively, respect students' cognition, stress heuristic teaching, avoid ineffective teaching ways and try to explore effective ways to improve English class conversation in the primary school and promote students' pragmatic ability

\section{References}

[1] Guojin Hou. The essence of pragmatics: pragmatics versus pragmatic mistakes. Beijing: World Book Publishing House. 2014.

[2] Huaikui LI. The research into 12 pragmatic ability: theory and practice. Shanghai: Shanghai Jiao Tong University Publishing House. 2013.

[3] Teng Ma. The inter-lingual pragmatic ability of English majors and the training mode. Beijing: China science Publishing House. 2013.

[4] Xiaoxi Sun. Development on L2 pragmatic competence. Shanghai: Shanghai Jiao Tong University Publishing House. 2009.

[5] Zhanhao Jiang. The research into pragmatic ability in the view of intermediary language pragmatics. Beijing: Beijing University Publishing House. 2013. 